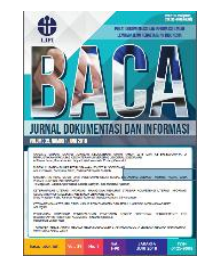

\title{
PERAN ARSIP DALAM PELESTARIAN CAGAR BUDAYA DI INDONESIA: SISTEMATIKA REVIEW
}

\author{
${ }^{1,2,3}$ Department of Library and Information Science, Faculty of Humanities, Univeritas Indonesia, \\ ${ }^{4}$ Faculty of Information Management, Universiti Teknologi MARA, Malaysia
}

"Korespondensi: fidan.safira@ui.ac.id

Diajukan: 31-10-2019; Direview: 05-02-2020; Diterima: 10-07-2020; Direvisi: 17-10-2020

\begin{abstract}
Archives have an important role in the preservation of cultural heritage buildings by the form of information about the history and development of cultural heritage buildings. Archives of heritage buildings are dynamic archives that are vital. Management thus must take priority. This study aims to the use of archives in the preservation of cultural heritage in Indonesia. A systematic review method was used with a qualitative approach. Collection data methods were conducted by planning, implementation, and reporting. The findings showed there are only two articles that review the archives in preservation heritage. Furthermore, our challenge is the lack of cultural heritage documents that most archives used were under regulations on the preservation of cultural heritage. Almost all articles thus showed a preservation model on physical forms and cultural heritage buildings.
\end{abstract}

\begin{abstract}
ABSTRAK
Arsip memiliki peranan penting dalam pelestarian bangunan cagar budaya berupa informasi mengenai sejarah, serta perkembangan dari bangunan cagar budaya. Arsip bangunan cagar budaya merupakan arsip dinamis yang bersifat vital, sehingga pengelolaannya harus diutamakan. Penelitian ini bertujuan untuk mengetahui penggunaan arsip dalam pelestarian cagar budaya di Indonesia. Penelitian ini menggunakan metode sistematika review dengan pendekatan kualitatif. Adapun metode pengumpulan datanya berupa tahap perencanaan, pelaksanaan, dan sintesa hasil penelusuran. Temuan dalam penelitian ini menunjukkan bahwa artikel jurnal terseleksi yang digunakan dalam penelitian, minim ulasan mengenai pentingnya arsip dalam pelestarian cagar budaya. Berdasarkan keseluruhan artikel jurnal terseleksi, hanya terdapat sekitar dua artikel jurnal yang mengulas mengenai arsip sebagai model pelestarian cagar budaya dan minimnya dokumen cagar budaya sebagai tantangan pelestarian cagar budaya. Selain itu, penjabaran mengenai peranan arsip dalam pelestarian cagar budaya berfokus pada dokumen yang berisikan mengenai regulasi pelestarian cagar budaya dimana enam artikel menunjukan model pelestarian yang berfokus pada wujud fisik dan bangunan cagar budaya.
\end{abstract}

Keywords: Archives; Preservation; Heritage; Culture; Systematic review; Indonesia

\section{PENDAHULUAN}

Indonesia memiliki sekitar 260 suku dan etnis yang tersebar dari ujung sabang hingga merauke (Kemendikbud, 2016). Setiap suku atau etnis tentu memiliki keunikan dan tradisi sebagai ciri khasnya dan warisan budaya bangsa. Keberagaman budaya di Indonesia merupakan warisan budaya bangsa yang harus dijaga dan dilestarikan. Warisan budaya merupakan produk atau hasil budaya fisik dari tradisi-tradisi yang berbeda dan prestasi-prestasi spiritual dalam bentuk nilai dari masa lalu yang menjadi elemen pokok dalam jati diri suatu kelompok atau bangsa (Risanti, 2011).

UNESCO (1992) menjelaskan bahwa warisan budaya terbagi menjadi dua, yaitu: tangible cultural dan intangible cultural. Bentuk warisan budaya yang termasuk dalam tangible cultural adalah seperti monumen, artefak, cagar budaya dan kawasan. Sedangkan yang termasuk dalam bentuk intangible cultural seperti bahasa, ritual dan tradisi. Kemendikbud mencatat ada sekitar 67.273 warisan budaya, meliputi 65.165 tangible cultural heritage dan 2.108 intangible cultural heritage (Hastuti, 2013).

Warisan budaya bangsa dapat berbentuk benda ataupun bukan benda penting untuk dilestarikan. Pelestarian warisan budaya merupakan bentuk upaya untuk tetap menjaga sejarah 
bangsa. Cagar budaya salah satunya yang memiliki sejarah erat dengan kisah masa lampau perkembangan bangsa. Cagar budaya berupa seperti bangunan cagar budaya, struktur cagar budaya, situs cagar budaya dan kawasan cagar budaya. Cagar budaya perlu dilestarikan karena memiliki nilai penting bagi sejarah, ilmu pengetahuan, pendidikan dan agama (UU No.11 Tahun 2010).

Pelestarian cagar budaya sudah menjadi urusan wajib pemerintah sebagaimana yang tercantum di UU No.11 Tahun 2010 tentang Cagar Budaya. Menurut UU tersebut, ada beberapa strategi dalam pelestarian cagar budaya, yaitu: penyelamatan, pengamanan, zonasi, pemeliharaan, dan pemugaran cagar budaya. Banyaknya pembangunan yang dilakukan saat ini membuat khawatir sekelompok orang yang peduli terhadap kelestarian cagar budaya. Seringkali cagar budaya dianggap sebagai bangunan-bangunan kuno dan sudah tidak sesuai lagi dengan perkembangan zaman (SS, 2012). Regulasi dari pemerintah tidak serta merta membuat hal tersebut telah dilaksanakan dengan baik.

Arsip dalam pelestarian cagar budaya memiliki peranan penting sebagai bukti terekam mengenai kisah dan perkembangan cagar budaya yang bersangkutan. Arsip merupakan salah satu alat bukti yang kuat. Rowat (1993) mengatakan bahwa semakin dekat ditemukan arsip mengenai sesuatu, semakin sedikit penyimpangan dalam sejarah dan semakin akurat sejarah tersebut. Arsip dapat dijadikan suatu bukti otentik keberadaan cagar budaya (Mirawati, 2012). Dengan demikian, cagar budaya yang sedang atau akan dibongkar dapat diselamatkan, dilindungi, dan dilestarikan sebagai suatu warisan budaya yang dapat dibanggakan.

Penelitian mengenai cagar budaya merupakan penelitian interdisipliner. Penelitian terkait cagar budaya dan arsip di Indonesia memang masih terbatas. Penelitian mengenai arsip dalam pelestarian cagar budaya dengan pendekatan sistematika review ini dianggap relevan. Sistematika review ini dapat dijadikan acuan untuk menentukan agenda riset dan masukan bagi penelitian selanjutnya. Penelitian ini ingin menunjukan penggunaan arsip dalam pelestarian cagar budaya melalui publikasi artikel mengenai cagar budaya.

\section{TINJAUAN PUSTAKA}

Arsip merupakan repositori memori yang dapat memberikan bukti tepercaya untuk mengetahui dan menyelidiki masa lalu (Effendhie, 2019). Keberadaan arsip ini dapat membantu dalam penyelidikan historis dan sebagai pengganti memori masa lalu. Arsip menjadi salah satu alat bukti yang kuat. Rowat (1993) mengatakan bahwa arsip berperan dalam mengkonstruksikan sejarah dan merefleksikan budaya. Peran tersebut menegaskan keterlibatan arsip dengan pelestarian cagar budaya sebagai warisan budaya. Arsip dapat menyimpan informasi mengenai nilai sejarah dan perkembangan pembangunan situs cagar budaya yang bersangkutan, sehingga, dapat berguna untuk diseminasi informasi untuk generasi berikutnya (Wibowo, 2018). Arsip dalam pelestarian cagar budaya dapat berupa arsip foto, dokumen pemugaran, struktur cagar, manuskrip, dsb. (Effendhie, 2019).

Penelitian mengenai pelestarian cagar budaya sebelumnya lebih melibatkan berbagai aspek lain dalam pelestarian cagar budaya. Penelitian Sulistyanto (2015), memfokuskan pada aspek keterlibatan sosial masyarakat dan kondisi lingkungan dalam pelestarian cagar budaya. Penelitian Al-Hamid (2018), memfokuskan pada pelaksanaan regulasi yang dilakukan oleh pemerintah setempat dalam pelestarian cagar budaya. Sedangkan penelitian Apriadi (2019), memfokuskan pada upaya pelestarian cagar budaya pada bangunan fisik dan faktor manajerial dalam pelestarian cagar budaya. Penelitian-penelitian tersebut merupakan penelitian lapangan dengan pengumpulan data primer melalui observasi dan wawancara.

Mengacu pada penelitian sebelumnya, belum banyak penelitian mengenai peran pentingnya arsip dalam pelestarian cagar budaya. Hal ini menunjukkan bahwa meskipun secara teori arsip berperan penting dalam pelestarian cagar budaya, belum banyak penelitian yang menunjukkan 
secara eksplisit peran arsip dalam pelestarian cagar budaya. Sehingga, perlu dibutuhkan penelitian yang mendukung hal tersebut.

\section{METODE}

Penelitian ini menggunakan metode sistematika review dengan pendekatan kualitatif. Menurut Klassen, et al., (1998) "a systematic review is a review in which there is a comprehensive search for relevant studies on a specific topic, and those identified are then appraised and synthesized according to a predetermined and explicit method". Gambar 1 menjelaskan fase pengumpulan data dengan sistematika review.

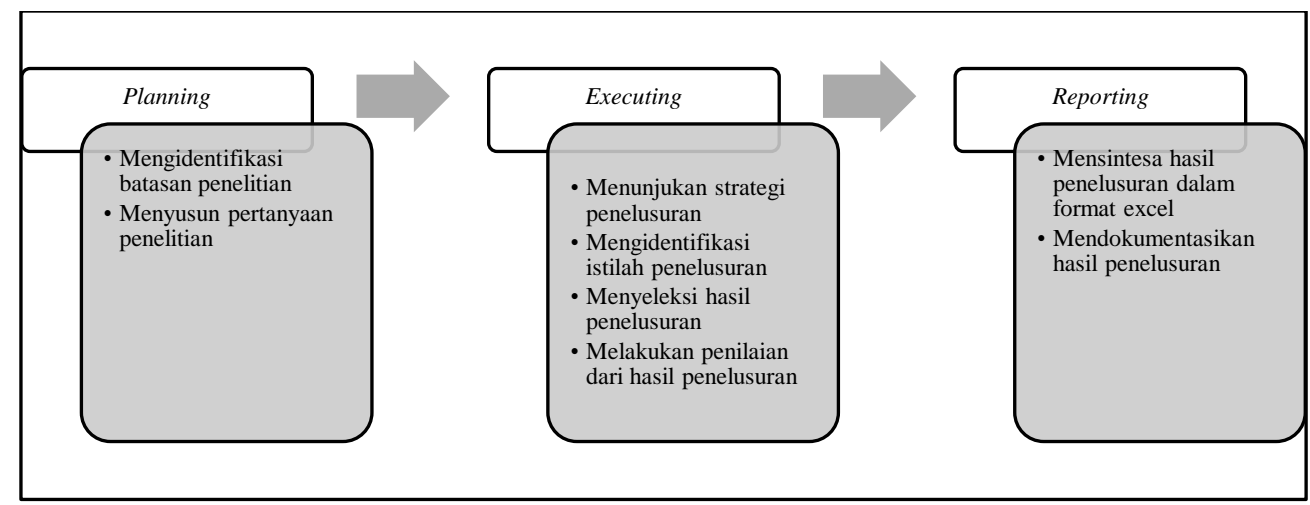

Gambar 1. Fase sistematika review (Adrian, 2016)

\section{Menyusun Pertanyaan Penelitian}

Pada tahap perencanaan (planning), peneliti melakukan batasan penelitian dan menyusun pertanyaan penelitian dengan menggunakan pendekatan PICOC (Population, Intervention, Comparison, Outcomes dan Context) dari Petticrew (2006). Batasan penelitian diperlukan agar artikel jurnal yang direview mampu menjawab pertanyaan penelitian secara spesifik. Adapun cakupan yang digunakan dalam menyusun pertanyaan penelitian terlihat pada Tabel 1 .

Tabel 1. Identifikasi Cakupan Pertanyaan Penelitian

\begin{tabular}{|l|l|}
\hline \multicolumn{1}{|c|}{ Kriteria } & \multicolumn{1}{c|}{ Cakupan } \\
\hline Population & Pelestarian cagar budaya dan arsip pelestarian cagar budaya \\
\hline Intervention & $\begin{array}{l}\text { Batasan pada model, pelaksanaan, dan tantangan pelestarian cagar budaya } \\
\text { di Indonesia }\end{array}$ \\
\hline Comparison & Tidak ditemukan \\
\hline Outcomes & $\begin{array}{l}\text { Arsip cagar budaya, model pelestarian, pelaksanaan pelestarian, dan } \\
\text { tantangan pelestarian cagar budaya di Indonesia }\end{array}$ \\
\hline Context & $\begin{array}{l}\text { Review dari hasil identifikasi pencarian pelestarian cagar budaya di } \\
\text { Indonesia }\end{array}$ \\
\hline
\end{tabular}

Mengacu pada Tabel 1, maka ditetapkan pertanyaan penelitian sebagai berikut.

RQ 1: Berapa banyak penelitian yang digunakan dalam penilain pelestarian cagar budaya di Indonesia?

RQ 2: Apa saja model yang digunakan dalam pelestarian cagar budaya di Indonesia?

RQ 3: Bagaimana tantangan dalam melakukan pelestarian cagar budaya di Indonesia?

RQ 4: Apa saja bentuk arsip yang mendukung dalam pelestarian cagar budaya di Indonesia? 


\section{Strategi Pencarian}

Pada tahap pelaksanaan (executing), penelitian ini menggunakan pendekatan PRISMA (Preferred Reporting Items for Systematic Reviews and Meta Analyses) yaitu strategi pencarian data ditunjukan melalui istilah pencarian yang digunakan, sumber data dari basis data (database) online, kriteria inklusi dan eksklusi yang digunakan, penilaian kualitas hasil penelusuran dan menjelaskan hasil pencarian data (Handayani, 2017).

\section{Istilah Pencarian}

Istilah pencarian merupakan kombinasi dan integrasi dari kosakata yang memiliki sinonim dengan menggunakan metode pencarian operator Boolean, seperti OR, AND dan NOT. Tabel 2 menunjukan kriteria istilah pencarian yang digunakan dalam penelitian.

Tabel 2. Istilah Pencarian

\begin{tabular}{|l|l|}
\hline \multicolumn{1}{|c|}{ Kriteria } & \multicolumn{1}{c|}{ Integrasi Sinonim } \\
\hline Population & Pelestarian cagar budaya OR Arsip pelestarian cagar budaya \\
\hline Intervention & $\begin{array}{l}\text { Arsip pelestarian cagar budaya OR model pelestarian cagar budaya OR } \\
\text { Tantangan pelestarian cagar budaya }\end{array}$ \\
\hline Method & Model OR pelaksanaan OR tantangan \\
\hline
\end{tabular}

Struktur istilah pencarian: (Pelestarian cagar budaya OR Arsip pelestarian cagar budaya) AND (Arsip pelestarian cagar budaya OR model pelestarian cagar budaya OR Tantangan pelestarian cagar budaya) AND (Model OR pelaksanaan OR tantangan).

\section{Sumber Literatur}

Penelitian ini menggunakan dua jenis database, yaitu (1) Portal GARUDA yang dikelola oleh Kementerian Riset, Teknologi dan Pendidikan Tinggi Republik Indonesia; dan (2) Google Scholar. Dua portal ini dipilih dan digunakan dalam cakupan penelitian mengenai arsip dalam pelestarian cagar budaya di Indonesia. Artikel jurnal yang digunakan dalam penelitian ini menggunakan metode penentuan sampel. Artikel jurnal yang relevan disimpan pada software reference management tools, yaitu Mendeley. Adapun batasan sitasi yang digunakan dalam penelitian adalah publikasi dari kurun waktu tahun 2009 - 2019 atau 10 tahun terakhir dari saat penelitian ini dilakukan.

\section{Kriteria Inklusi dan Eksklusi}

Kriteria inklusi dan eksklusi ini digunakan untuk memilah artikel jurnal yang layak untuk menjawab pertanyaan penelitian ini (Handayani, 2017). Adapun kriteria inklusi dan eksklusi dalam penelitian ini dapat dilihat pada Tabel 3

Tabel 3. Kriteria Inklusi dan Eksklusi

\begin{tabular}{|l|l|}
\hline \multicolumn{1}{|c|}{ Inklusi } & \multicolumn{1}{c|}{ Eksklusi } \\
\hline $\begin{array}{l}\text { Semua artikel jurnal yang publikasi dengan } \\
\text { Bahasa Indonesia. }\end{array}$ & $\begin{array}{l}\text { Artikel jurnal yang dipublikasikan menggunakan } \\
\text { selain Bahasa Indonesia }\end{array}$ \\
\hline $\begin{array}{l}\text { Semua artikel jurnal yang dipublikasikan } \\
\text { mulai tahun 2009 hingga tahun 2019 }\end{array}$ & $\begin{array}{l}\text { Artikel jurnal yang dipublikasikan sebelum atau } \\
\text { sesudah tahun 2009 - 2019 }\end{array}$ \\
\hline $\begin{array}{l}\text { Artikel jurnal yang fokus pada pelestarian } \\
\text { cagar budaya, baik upaya, tantangan dan } \\
\text { kebijakan }\end{array}$ & $\begin{array}{l}\text { Artikel jurnal yang tidak sesuai dengan cakupan } \\
\text { batasan penelitian ini }\end{array}$ \\
\hline & $\begin{array}{l}\text { Artikel jurnal yang memiliki duplikasi dalam } \\
\text { database }\end{array}$ \\
\hline & $\begin{array}{l}\text { Artikel yang memuat penjelasan mengenai } \\
\text { keruangan dan partisipasi masyarakat dalam } \\
\text { judul }\end{array}$ \\
\hline
\end{tabular}




\section{Penilaian Kualitas Hasil Penelusuran}

Penilaian kualitas hasil penelusuran bertujuan untuk mengevaluasi kualitas artikel jurnal dan kebermanfaatan data yang didapatkan. Adapun pertanyaan yang mendukung untuk menilai hasil penelusuran (Tabel 4). Setiap pertanyaan memiliki tiga pilihan jawaban, yaitu: Ya = 1; Ragu-ragu $=0.5$; Tidak $=0$ (Adrian, et. al, 2016).

Tabel 4. Kriteria Penilaian berdasarkan Hasil Penelusuran

\begin{tabular}{|c|l|l|}
\hline $\begin{array}{c}\text { Tingkat } \\
\text { Kualitas }\end{array}$ & \multicolumn{1}{|c|}{ Pertanyaan } & \multicolumn{1}{|c|}{ Jawaban } \\
\hline Q 1 & $\begin{array}{l}\text { Apakah ada deskripsi yang jelas tentang maksud dan tujuan } \\
\text { penelitian ini? }\end{array}$ & $\begin{array}{l}\text { Ya/ Ragu- } \\
\text { Ragu/ Tidak }\end{array}$ \\
\hline Q 2 & Apakah penelitian ini didasarkan pada review suatu kasus? & Ya/ Tidak \\
\hline Q 3 & $\begin{array}{l}\text { Apakah penelitian ini merupakan "pelajaran yang diambil dari } \\
\text { suatu kasus" atau laporan berdasarkan pendapat ahli? }\end{array}$ & Ya/ Tidak \\
\hline Q 4 & $\begin{array}{l}\text { Apakah penelitian ini menjelaskan penggunaan arsip dalam } \\
\text { pelestarian cagar budaya secara detail? }\end{array}$ & $\begin{array}{l}\text { Ya/ Ragu- } \\
\text { Ragu/ Tidak }\end{array}$ \\
\hline
\end{tabular}

\section{HASIL DAN PEMBAHASAN}

Berdasarkan strategi penelusuran pada dua database jurnal ilmiah (GARUDA dan Google Schoolar) adalah 26 artikel jurnal. Setelah dilakukan tahap seleksi duplikasi dari antar dan dalam database, 23 artikel jurnal terseleksi. Kemudian, dalam pengumpulan full text pada masing-masing artikel jurnal, 3 artikel jurnal tidak dapat diakses secara penuh. Peneliti melakukan eksklusi berdasarkan konten artikel jurnal yang dianggap tidak relevan dengan fokus penelitian, sehingga artikel jurnal yang memuat bahasan mengenai keruangan dan partisipasi masyarakat sebanyak tujuh artikel jurnal tidak diikutsertakan. Total artikel jurnal yang akan direview dalam penelitian ini berjumlah 13 artikel jurnal. Adapun rincian yang dilakukan dalam seleksi artikel jurnal dapat dilihat pada Gambar 2.

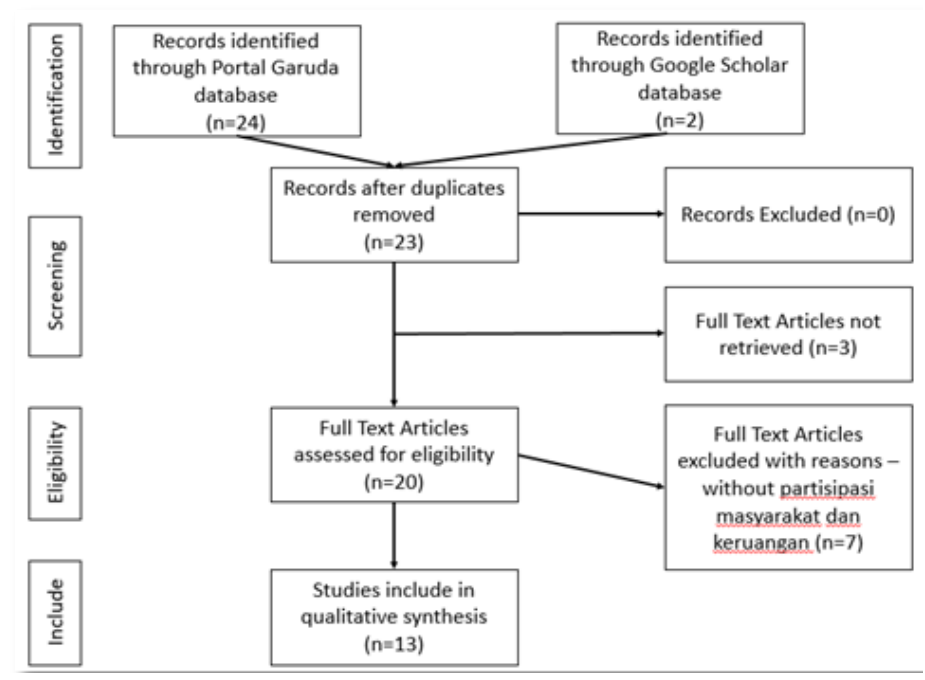

Gambar 2. Tahap seleksi sistematika review

Berdasarkan data yang dikumpulkan dan dilakukan penilaian kualitas hasil penelusuran berdasarkan kriteria, hasil penilaian menunjukan nilai terendah, yaitu nilai 2 ( 2 artikel), nilai 2,5 (1 artikel), nilai 3 (5 artikel), nilai 3,5 (3 artikel), dan nilai 4 (2 artikel), sebagaimana yang terlihat pada Gambar 3. 


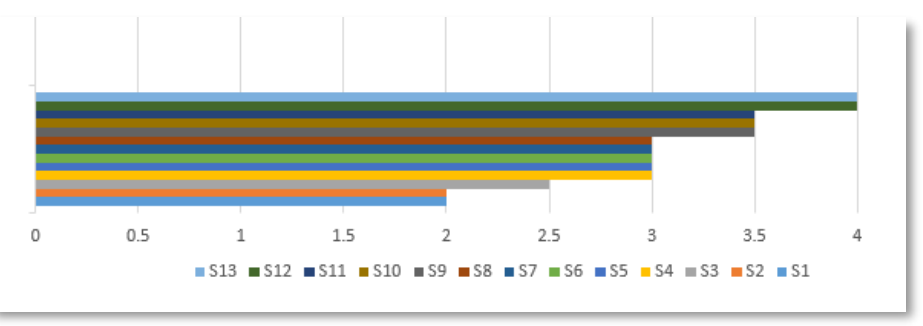

Gambar 3. Penilaian kualitas hasil penelusuran

Selanjutnya, peneliti akan mengulas jawaban dari pertanyaan penelitian pada Bagian 2.1 berdasarkan hasil review peneliti pada artikel jurnal terseleksi yang digunakan dalam penelitian ini. Artikel jurnal terseleksi mengenai pelestarian cagar budaya yang digunakan dalam penelitian ini merupakan artikel jurnal interdisipliner. Adapun rincian dari artikel jurnal terseleksi dalam Tabel 5 .

Tabel 5. Daftar Artikel Jurnal Terseleksi

\begin{tabular}{|c|c|c|c|c|}
\hline Kode & Judul & Jurnal & $\begin{array}{c}\text { Penulis/ } \\
\text { Tahun }\end{array}$ & Tujuan \\
\hline $\mathrm{S} 1$ & $\begin{array}{l}\text { Rekonstruksi Pelestarian } \\
\text { Cagar Budaya Berbasis } \\
\text { Nilai Kesejahteraan }\end{array}$ & $\begin{array}{l}\text { Meta Yuridis Vol } \\
2, \text { No } 1 \text { (2019) }\end{array}$ & $\begin{array}{l}\text { Sunardi/ } \\
2019\end{array}$ & $\begin{array}{l}\text { Menguji faktor-faktor yang berpengaruh } \\
\text { terhadap pelestarian cagar budaya; } \\
\text { mengetahui dampak negatif pelestarian } \\
\text { benda cagar budaya; mengetahui } \\
\text { rekonstruksi pelestarian cagar budaya yang } \\
\text { berbasis nilai kesejahteraan. }\end{array}$ \\
\hline $\mathrm{S} 2$ & $\begin{array}{l}\text { Efektivitas Pelestarian } \\
\text { Cagar Budaya Dalam } \\
\text { Undang-Undang Nomor } 11 \\
\text { Tahun } 2010 \text { Tentang Cagar } \\
\text { Budaya }\end{array}$ & $\begin{array}{l}\text { Jurnal Legislasi } \\
\text { Indonesia Vol 15, } \\
\text { No } 1 \text { (2018): } \\
\text { Jurnal Legislasi } \\
\text { Indonesia - Maret } \\
2018 \\
\end{array}$ & $\begin{array}{l}\text { Bagus } \\
\text { Prasetyo/ } \\
2018\end{array}$ & $\begin{array}{l}\text { Mengetahui efektivitas pelaksanaan } \\
\text { pengawasan pelestarian cagar budaya } \\
\text { berdasarkan UU Cagar Budaya. }\end{array}$ \\
\hline S3 & $\begin{array}{l}\text { Arsip Pemugaran Candi } \\
\text { Sebagai Pelestarian Cagar } \\
\text { Budaya }\end{array}$ & $\begin{array}{l}\text { WARTA ARSIP, } \\
\text { Desember 2018, } \\
\text { VII (2). pp. 12-16. } \\
\text { ISSN 2442-2894 } \\
\end{array}$ & $\begin{array}{l}\text { Endang } \\
\text { Fatmawati/ } \\
2018\end{array}$ & $\begin{array}{l}\text { Menjelaskan pentingnya arsip pemugaran } \\
\text { cagar budaya sebagai bentuk pelestarian } \\
\text { cagar budaya. }\end{array}$ \\
\hline S4 & $\begin{array}{l}\text { Peranan Balai Pelestarian } \\
\text { Cagar Budaya (BPCB) } \\
\text { Aceh Dalam Pelestarian } \\
\text { Situs-Situs Bersejarah Di } \\
\text { Kota Banda Aceh Tahun } \\
1990 \text { - } 2015\end{array}$ & $\begin{array}{l}\text { Jurnal Ilmiah } \\
\text { Mahasiswa } \\
\text { Jurusan } \\
\text { Pendidikan } \\
\text { Sejarah Vol 2, No } \\
1 \text { (2017): Januari } \\
2017\end{array}$ & $\begin{array}{l}\text { Oga Umar } \\
\text { Dhani, Hus } \\
\text { aini, Abdull } \\
\text { ah, Teuku/ } \\
2017\end{array}$ & $\begin{array}{l}\text { Menjelaskan peran dan kebijakan, } \\
\text { perkembangan dan kendala yang dialami } \\
\text { BPCB dalam melestarikan situs-situs } \\
\text { bersejarah di Kota Banda Aceh. }\end{array}$ \\
\hline S5 & $\begin{array}{l}\text { Implementasi Undang- } \\
\text { Undang Nomor } 11 \text { Tahun } \\
2010 \text { Terhadap Pelestarian } \\
\text { Benda Cagar Budaya Di } \\
\text { Kecamatan Ambarawa } \\
\text { Kabupaten Semarang }\end{array}$ & $\begin{array}{l}\text { Hukum dan } \\
\text { Masyarakat } \\
\text { Madani Vol 6, No } \\
1 \text { (2016): Januari }\end{array}$ & $\begin{array}{l}\text { Ratna } \\
\text { Herawati/ } \\
2016\end{array}$ & $\begin{array}{l}\text { Menganalisis mengenai implementasi UU } \\
\text { No } 11 \text { Tahun } 2010 \text { terhadap pelestarian } \\
\text { benda cagar budaya di Kecamatan } \\
\text { Ambarawa Kabupaten Semarang; } \\
\text { mengetahui kendala implementasi UU No } \\
11 \text { Tahun } 2010 \text { terhadap pelestarian benda } \\
\text { cagar budaya di Kecamatan Ambarawa } \\
\text { Kabupaten Semarang. }\end{array}$ \\
\hline S6 & $\begin{array}{l}\text { Pelestarian Benda Cagar } \\
\text { Budaya Di Objek Wisata } \\
\text { Museum Sang Nila Utama } \\
\text { Provinsi Riau }\end{array}$ & $\begin{array}{l}\text { Jurnal Online } \\
\text { Mahasiswa (JOM) } \\
\text { Bidang Ilmu } \\
\text { Sosial dan Ilmu } \\
\text { Politik Vol 2, No } \\
1 \text { (2015) } \\
\end{array}$ & $\begin{array}{l}\text { Martina } \\
\text { Butar- } \\
\text { butar, Arief } \\
\text {, Andi M } \\
\text { Rifiyan/ } \\
2015\end{array}$ & $\begin{array}{l}\text { Mengetahui bentuk kegiatan pelestarian } \\
\text { benda cagar budaya yang ada di objek } \\
\text { wisata museum sang nila utama Provinsi } \\
\text { Riau. }\end{array}$ \\
\hline S7 & $\begin{array}{l}\text { Penciptaan Buku Referensi } \\
\text { Masjid Tua Pada Abad XV } \\
\text { Di Surabaya Sebagai } \\
\text { Upaya Pelestarian Cagar } \\
\text { Budaya }\end{array}$ & $\begin{array}{l}\text { Jurnal Art } \\
\text { Nouveau Vol 4, } \\
\text { No } 1(2015) \text { : } \\
\text { Mengemas Nilai } \\
\text { Lokal dalam } \\
\text { Industri } \\
\text { Komersial } \\
\end{array}$ & $\begin{array}{l}\text { Duanda Lis } \\
\text { Septiawan, } \\
\text { Muh. Bahru } \\
\text { ddin, Sutik } \\
\text { no/ } 2015\end{array}$ & $\begin{array}{l}\text { Membuat buku referensi tentang masjid tua } \\
\text { di Surabaya sebagai upaya melestarikan } \\
\text { cagar budaya; mendokumentasikan dan } \\
\text { memberikan informasi mengenai masjid } \\
\text { tua di Surabaya kepada masyarakat. }\end{array}$ \\
\hline S8 & $\begin{array}{l}\text { Analisis Pengelolaan Dan } \\
\text { Pelestarian Cagar Budaya } \\
\text { Sebagai Wujud } \\
\text { Penyelenggaraan Urusan } \\
\text { Wajib Pemerintahan } \\
\text { Daerah (Studi Pada }\end{array}$ & $\begin{array}{l}\text { Jurnal } \\
\text { Administrasi } \\
\text { Publik Vol 2, No } \\
5 \text { (2014) }\end{array}$ & $\begin{array}{l}\text { Khalid } \\
\text { Rosyadi/ } \\
2014\end{array}$ & $\begin{array}{l}\text { Mengetahui pengelolaan dan pelestarian } \\
\text { cagar budaya situs Majapahit Trowulan; } \\
\text { mengetahui aktor-aktor yang terlibat dalam } \\
\text { pengelolaan dan pelestarian cagar budaya } \\
\text { situs Majapahit Trowulan. }\end{array}$ \\
\hline
\end{tabular}




\begin{tabular}{|c|c|c|c|c|}
\hline & $\begin{array}{l}\text { Pengelolaan Dan } \\
\text { Pelestarian Situs Majapahit } \\
\text { Kecamatan Trowulan } \\
\text { Kabupaten Mojokerto) }\end{array}$ & & & \\
\hline S9 & $\begin{array}{l}\text { Pelestarian Situs Cagar } \\
\text { Budaya Plawangan } \\
\text { Rembang Perspektif } \\
\text { Undang-Undang Cagar } \\
\text { Budaya }\end{array}$ & $\begin{array}{l}\text { Pandecta: } \\
\text { Research Law } \\
\text { Journal Vol 9, No } \\
2 \text { (2014): } \\
\text { Pandecta } \\
\text { December } 2014\end{array}$ & $\begin{array}{l}\text { Deky } \\
\text { Akbar/ } \\
2014\end{array}$ & $\begin{array}{l}\text { Menganalisis kebijakan pelestarian Situs } \\
\text { Cagar Budaya Plawangan Kabupaten } \\
\text { Rembang dilihat dari perspektif Undang- } \\
\text { Undang Nomor } 11 \text { Tahun } 2010 \text { Tentang } \\
\text { Cagar Budaya dan menganalisis model } \\
\text { yang relevan dalam Pelestarian Situs Cagar } \\
\text { Budaya Plawangan Kabupaten Rembang. }\end{array}$ \\
\hline $\mathrm{S} 10$ & $\begin{array}{l}\text { Strategi Perlindungan } \\
\text { Terhadap Arsitektur } \\
\text { Tradisional Untuk Menjadi } \\
\text { Bagian Pelestarian Cagar } \\
\text { Budaya Dunia }\end{array}$ & $\begin{array}{l}\text { Nalars Vol 13, No } \\
1 \text { (2014): } \\
\text { NALARS Volume } \\
13 \text { Nomor } 1 \\
\text { Januari } 2014\end{array}$ & $\begin{array}{l}\text { Zairin Zain/ } \\
2014\end{array}$ & $\begin{array}{l}\text { Mengetahui strategi perlindungan terhadap } \\
\text { arsitektur tradisional beserta artefaknya } \\
\text { sebagai bagian dari upaya pelestarian cagar } \\
\text { budaya dunia. }\end{array}$ \\
\hline $\mathrm{S} 11$ & $\begin{array}{l}\text { Implementasi Perda Kota } \\
\text { Surabaya No } 5 \text { Tahun } 2005 \\
\text { Tentang Pelestarian } \\
\text { Bangunan Dan/Atau } \\
\text { Lingkungan Cagar Budaya } \\
\text { Di Kota Surabaya (Suatu } \\
\text { Studi Pada Dinas } \\
\text { Kebudayaan Dan } \\
\text { Pariwisata Kota Surabaya) }\end{array}$ & $\begin{array}{l}\text { Jurnal } \\
\text { Administrasi } \\
\text { Publik Vol 1, No } \\
5 \text { (2013) }\end{array}$ & $\begin{array}{l}\text { Heni } \\
\text { Kurnia/ } \\
2013\end{array}$ & $\begin{array}{l}\text { Mengetahui dan menganalisis } \\
\text { implementasi Perda Kota Surabaya Nomor } \\
5 \text { Tahun 2005, serta mengetahui dan } \\
\text { menganalisis faktor-faktor penghambat dan } \\
\text { pendukung implementasi Perda tersebut. }\end{array}$ \\
\hline $\mathrm{S} 12$ & $\begin{array}{l}\text { Harmonisasi UU No. } 11 \\
\text { Tahun } 2010 \text { Tentang Cagar } \\
\text { Budaya Dalam Upaya } \\
\text { Pelestarian Benda Cagar } \\
\text { Budaya Kota Semarang }\end{array}$ & $\begin{array}{l}\text { Jurnal Abdimas } \\
\text { Vol } 17, \text { No } 2 \\
(2013)\end{array}$ & $\begin{array}{l}\text { Andry } \\
\text { Setiawan } \\
\text { dan Dewi } \\
\text { Sulistianing } \\
\text { sih/ } 2013\end{array}$ & $\begin{array}{l}\text { Mengetahui eksistensi benda-benda Cagar } \\
\text { Budaya yang ada di Kota Semarang; } \\
\text { mengetahui implementasi UU No. 11 } \\
\text { Tahun } 2010 \text { dalam memberikan } \\
\text { perlindungan Benda Cagar Budaya Kota } \\
\text { Semarang; mengetahui hambatan dalam } \\
\text { pelaksanaan pelestarian benda Cagar } \\
\text { Budaya di Kota Semarang. }\end{array}$ \\
\hline S13 & $\begin{array}{l}\text { Desentralisasi Dan Sumber } \\
\text { Daya Aparatur: } \\
\text { Problematika Pelaksanaan } \\
\text { Desentralisasi Pelestarian } \\
\text { Cagar Budaya Di Provinsi } \\
\text { Sumatera Barat, Riau, Dan } \\
\text { Kepulauan Riau }\end{array}$ & $\begin{array}{l}\text { Jurnal Ilmu Sosial } \\
\text { dan Ilmu Politik } \\
\text { Vol 15, No } 3 \\
\text { (2012): Dinamika } \\
\text { Politik } \\
\text { Desentralisasi }\end{array}$ & $\begin{array}{l}\text { Sri } \\
\text { Sugiharti/ } \\
2012\end{array}$ & $\begin{array}{l}\text { Mendiskusikan tentang pelaksanaan } \\
\text { desentralisasi khususnya bidang pelestarian } \\
\text { cagar budaya di Provinsi Sumatera Barat, } \\
\text { Riau, dan Kepulauan Riau. }\end{array}$ \\
\hline
\end{tabular}

\section{RQ 1: Berapa banyak penelitian yang digunakan dalam penilaian pelestarian cagar budaya di Indonesia?}

Artikel jurnal yang terseleksi dan digunakan dalam penilaian mengenai pelestarian cagar budaya ini sebanyak 13 artikel jurnal, keseluruhannya menggunakan pendekatan kualitatif (Gambar 4). Namun, terdapat dua metode dalam pengumpulan data yang digunakan, yaitu metode pengumpulan data melalui studi kepustakaan sebanyak 5 artikel jurnal. Sebanyak 8 artikel jurnal lainnya menggunakan metode pengumpulan data: wawancara, observasi, dan dokumentasi.

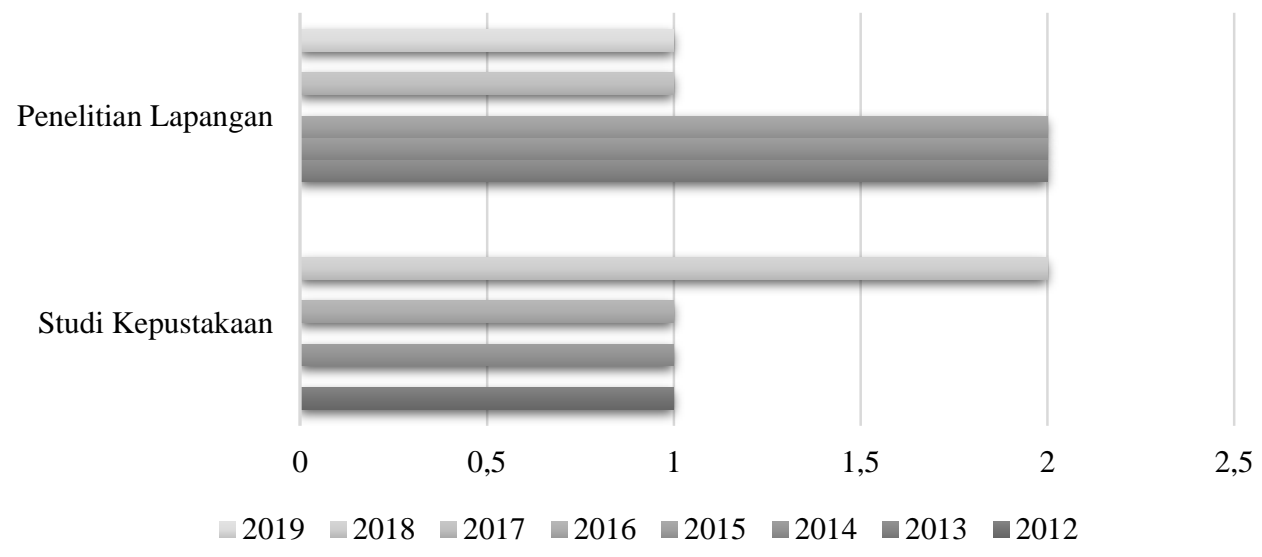

Gambar 4. Distribusi penggunaan metode dalam artikel 
Kemudian, distribusi tahun yang digunakan artikel jurnal yang digunakan dalam penelitian, yaitu artikel jurnal yang dipublikasikan dari tahun 2009 hingga 2019. Namun, hasil temuannya hanya ditemukan artikel jurnal yang diterbitkan pada tahun 2012 hingga 2019. Sebanyak 1 artikel jurnal yang dipublikasikan di tahun 2012, 2016, 2017 dan 2018 dimana masing-masing yaitu artikel S13, S5, S4 dan S3. Dua artikel jurnal dari publikasi tahun 2013, yaitu S12 dan S11. Dua artikel jurnal juga yang publikasi pada tahun 2015, yaitu artikel jurnal S6 dan S7. Tiga artikel jurnal dari publikasi tahun 2014, yaitu S8, S9 dan S10. Dua artikel jurnal dari publikasi tahun 2019, yaitu S1 dan S2. Kecenderungan artikel jurnal terseleksi dalam penelitian mengenai pelestarian cagar budaya adalah dengan menggunakan pendekatan kualitatif dengan metode pengumpulan data berupa studi lapangan. Meskipun tidak dapat dikatakan kecenderungan, artikel jurnal terseleksi paling banyak ditemukan pada publikasi pada tahun 2014, yaitu sebanyak 3 judul artikel jurnal. Sedangkan pada tahun-tahun lainnya, berkisar antara 1 atau 2 artikel jurnal.

\section{RQ 2: Apa saja model yang digunakan dalam pelestarian cagar budaya di Indonesia?}

Mengacu pada UU No.11 Tahun 2010 tentang Cagar Budaya, model pelestarian cagar budaya meliputi: penyelamatan, pengamanan, zonasi, pemeliharaan, dan pemugaran cagar budaya. Berdasarkan review dari artikel jurnal yang digunakan dalam penelitian ini, model pelestarian cagar budaya yang dapat digunakan ataupun direkomendasikan (Gambar 5).

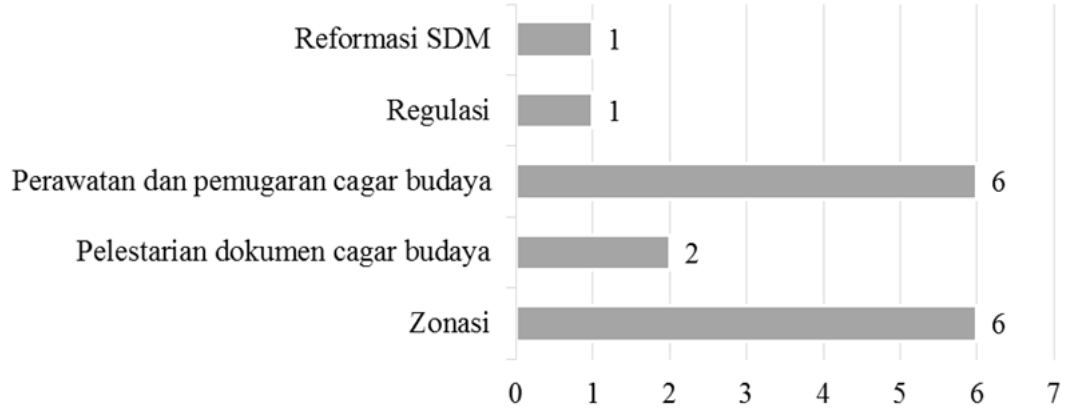

Gambar 5. Distribusi model pelestarian cagar budaya

Sebanyak 6 artikel jurnal menggunakan model zonasi sebagai upaya pelestarian cagar budaya, 6 artikel jurnal pula yang menunjukan model perawatan dan pemugaran situs cagar budaya sebagai bentuk pelestarian cagar budaya, sedangkan hanya 2 artikel jurnal saja yang menunjukkan pelestarian dokumen mengenai cagar budaya tersebut sebagai model pelestarian cagar budaya. Gambar 5 juga menunjukkan model pelestarian cagar budaya berdasarkan undang-undang yang digunakan dan direkomendasikan oleh artikel jurnal. Terdapat model pelestarian lainnya, misalnya reformasi sumber daya manusia agar dapat mendukung pelestarian cagar budaya. Hal ini diberikan berdasarkan latar belakang masalah yang ditemukan bahwasannya tantangan dalam pelestarian cagar budaya disebabkan oleh sumber daya manusia dengan kinerja yang buruk (Sugiharta, 2010), sehingga diperlukan reformasi sumber daya manusia untuk mendukung pelestarian cagar budaya. Model selanjutnya yang tidak tertera dalam undang-undang adalah perlunya ketegasan regulasi dari pemerintah setempat dalam pelestarian cagar budaya (Akbar, 2014; Prasetyo, 2018; Herawati, 2016). Hal ini juga berkaitan dengan tantangan yang banyak menunjukan ketidakadaannya regulasi yang jelas dari pemerintah setempat mengenai pelestarian cagar budaya (Akbar, 2014; Prasetyo, 2018; Herawati, 2016 ).

\section{RQ 3: Bagaimana tantangan dalam melakukan pelestarian cagar budaya di Indonesia?}

Pelestarian cagar budaya tidak serta merta dapat berjalan dengan baik (Kurnia, 2013; Rosyadi, 2014; Herawati, 2016; Dhani, 2017). Terdapat beberapa faktor yang kerap kali menjadi tantangan 
dalam pelestarian cagar budaya. Berdasarkan identifikasi pada artikel jurnal terseleksi, terdapat 7 faktor yang dinyatakan sebagai faktor yang menjadi tantangan dalam pelestarian cagar budaya. Ketujuh faktor tersebut adalah: kebijakan atau regulasi, terbatasnya sumberdaya anggaran, terbatasnya sumber daya ahli, rendahnya sinergitas stakeholder, minimnya kesadaran masyarakat setempat mengenai pentingnya pelestarian cagar budaya, tidak adanya dokumen yang relevan mengenai cagar budaya yang bersangkutan dan faktor lingkungan. Adapun distribusi faktor yang menjadi tantangan dalam pelestarian cagar budaya dalam artikel jurnal terseleksi dapat dilihat pada Gambar 6.

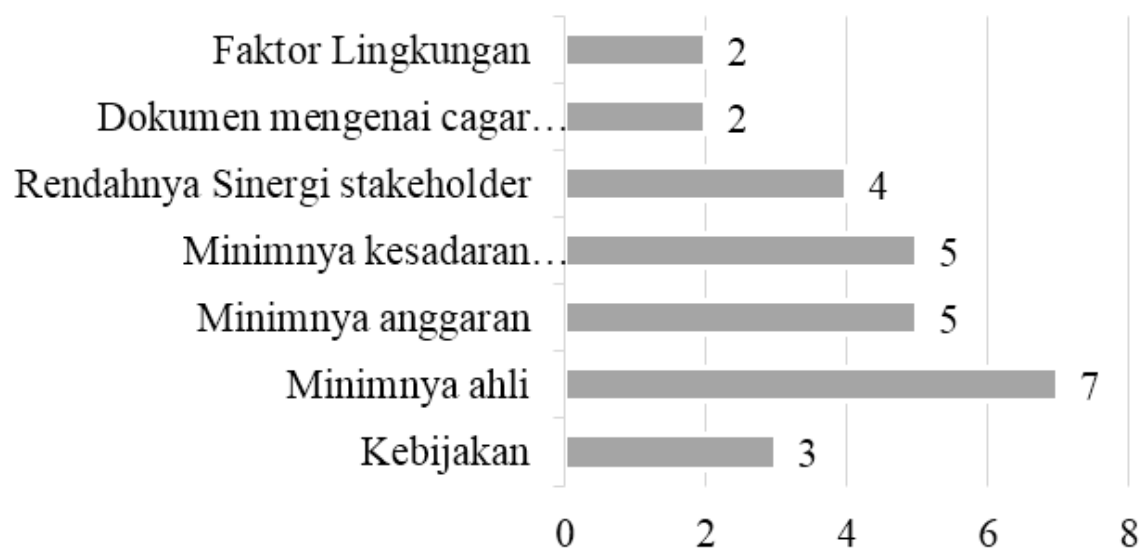

Gambar 6. Tantangan pelestarian cagar budaya

Kecenderungan artikel jurnal terseleksi menunjukan bahwa terbatasnya ahli dalam pelestarian cagar budaya menjadi tantangan utama. Hal tersebut ditunjukan oleh 7 artikel jurnal terseleksi (S2, S8, S3; S12; S1; S10; S5). Faktor selanjutnya yang menjadi tantangan pelestarian cagar budaya dengan nilai dari 5 jurnal terseleksi adalah faktor terbatasnya anggaran untuk melakukan pelestarian cagar budaya dan minimnya kesadaran masyarakat setempat mengenai pelestarian cagar budaya (S2, S4, S11, S10; S8). Faktor rendahnya sinergi dari stakeholder dalam pelestarian cagar budaya termasuk faktor yang menjadi tantangan dan tercantum pada 4 artikel jurnal terseleksi (S10; S4, S12, S5). Faktor tidak adanya regulasi atau kebijakan yang jelas mengenai pelestarian cagar budaya, terutama pada daerah menjadi tantangan dan tercantum pada 3 artikel jurnal terseleksi (S1; S8; S4). Faktor lingkungan dan faktor tidak tersedianya dokumen mengenai cagar budaya yang bersangkutan menjadi tantangan dalam pelestarian cagar budaya dan masing-masing tercantum pada 2 artikel jurnal terseleksi.

RQ 4: Apa saja bentuk arsip yang mendukung dalam pelestarian cagar budaya di Indonesia? Penggunaan arsip dalam pelestarian cagar budaya tidak tercantum pada seluruh artikel jurnal terseleksi. Berdasarkan review pada artikel jurnal terseleksi, terdapat 2 bentuk arsip yang dapat digunakan dalam pelestarian cagar budaya, yaitu: (1) regulasi atau kebijakan mengenai pelestarian cagar budaya; dan (2) dokumen yang berisikan informasi mengenai situs cagar budaya yang bersangkutan. Gambar 7 menunjukkan distribusi penggunaan arsip dalam pelestarian cagar budaya. 


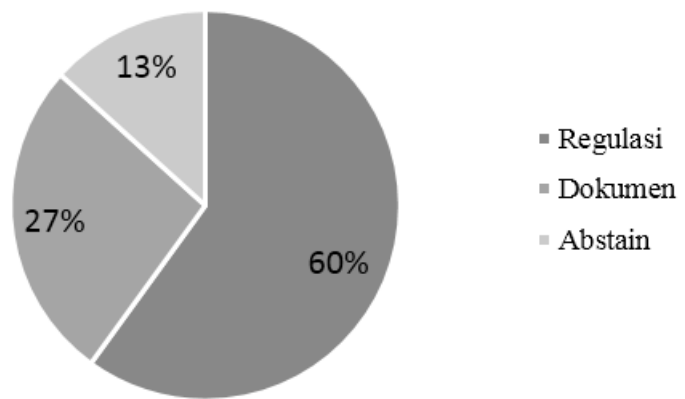

Gambar 7. Bentuk arsip dalam pelestarian cagar budaya

Sebanyak 9 artikel jurnal terseleksi menggunakan arsip berupa kebijakan atau regulasi dalam pelestarian cagar budaya sebagai acuan (S1, S2, S4, S7, S8, S9, S10, S11, S12). Beberapa regulasi yang digunakan dalam artikel jurnal terseleksi diantaranya adalah UU No.11 Tahun 2010 tentang Cagar Budaya dan peraturan daerah setempat mengenai pelestarian cagar budaya. Terdapat 4 artikel jurnal terseleksi yang menunjukan penggunaan arsip dokumen dalam pelestarian cagar budaya (S6, S8, S10, S13). Adapun bentuk arsip yang dapat digunakan, diantaranya adalah foto, laporan penelitian, buku referensi, flyer, poster, memoranda kebijakan, paper isu kebijakan, ringkasan eksekutif, appendix, pengumuman berita, dan kinerja kebijakan. Sedangkan 2 artikel jurnal terseleksi lainnya, tidak menunjukan penggunaan arsip dalam pelestarian cagar budaya (S3, S5).

\section{Diskusi}

Peranan arsip dalam pelestarian cagar budaya adalah apabila terjadi perubahan terhadap sebuah bangunan bersejarah, baik perubahan secara alami maupun perubahan akibat perbuatan manusia, diperlukan sebuah pedoman untuk dapat membangunnya kembali (SS, 2012). Pedoman tersebut merupakan hasil dokumentasi berupa gambar dari suatu bangunan disebut pula dengan arsip kearsitekturan. Arsip kearsitekturan untuk gedung atau bangunan yang penting dikategorikan sebagai arsip vital (Krihanta, 2012).

Arsip vital merupakan arsip dinamis yang memerlukan perlakuan khusus baik dalam hal pengamanan maupun perlindungan karena informasi yang dimilikinya sangat terkait dengan keberadaan dan kelangsungan organisasi itu sendiri (Krihanta, 2013). Arsip vital merupakan arsip yang sangat penting dan masuk dalam kategori kelas satu. Pengelolaan arsip kearsitekturan harus lebih diutamakan dari pada pengelolaan arsip lainnya. Mirawati (2012) mengungkapkan bahwa arsip kearsitekturan dapat menceritakan dengan rinci suatu bangunan masa kolonial ketika mulai dibangun. Mengelola arsip dari situs cagar budaya dapat diartikan sebagai salah satu bentuk upaya melakukan pelestarian cagar budaya.

Cunningham, Hubert-Jan Henkert, et al. (2005) menunjukan dokumen merupakan salah satu strategi pelestarian cagar budaya. Berdasarkan identifikasi artikel jurnal terseleksi pada penelitian ini, tidak keseluruhan artikel jurnal terseleksi mengungkapkan pentingnya peranan arsip dalam pelestarian cagar budaya. Kecenderungan penggunaan arsip dalam pelestarian cagar budaya adalah dokumen berupa regulasi dari UU No.11 Tahun 2010 Tentang Cagar Budaya. Artikel jurnal terseleksi lebih banyak menunjukan upaya pelestarian bangunan cagar budaya dalam wujudnya. Peranan arsip maupun informasi yang tersimpan mengenai sejarah bangunan cagar budaya dapat dikatakan belum dianggap sebagai suatu yang krusial untuk dilestarikan dari pada bentuk atau wujud bangunan cagar budaya itu sendiri.

Salah satu artikel jurnal terseleksi menujukkan upayanya dalam melakukan pelestarian dari situs cagar budaya melalui pembuatan buku referensi mengenai masjid tua abad ke-XV di Kota Surabaya (Septiawan, 2015). Salah satu artikel jurnal terseleksi yang berasal dari bidang perpustakaan dan ilmu informasi (Fahmawati, 2018) memberikan contoh mengenai arsip 
pemugaran candi sebagai bentuk pelestarian cagar budaya. Contoh tersebut berasal dari arsip pemugaran Candi Borobudur yang masih dijaga dalam rentang waktu 10 tahun, sejak 1973 hingga 1983. Arsip tersebut menyimpan informasi penting tentang sejarah pelestarian Candi Borobudur, misalnya 70 ribu foto pemugaran, 13 ribu slide foto, rol film, gambar berskala hingga daftar kehadiran pekerja yang terlibat dalam pemugaran candi juga masih tersimpan rapi. Peran penting arsip pemugaran Candi Borobudur ini kemudian mengantarkan Candi Borobudur mendapatkan pengakuan dari UNESCO sebagai Memory of the World dan pernah masuk dalam polling sebagai salah satu dari tujuh keajaiban dunia.

Arsip yang cenderung diulas dalam artikel jurnal terseleksi adalah arsip regulasi atau kebijakan pemerintah setempat mengenai pelestarian cagar budaya. Adapun regulasi yang selalu tercantum dalam artikel jurnal terseleksi adalah UU No.11 Tahun 2010 Tentang Cagar Budaya dan regulasi berupa peraturan daerah dari pemerintah setempat. Zain (2014) mengatakan bahwa dokumen merupakan cara yang tepat dan efektif untuk konservasi agar tetap memiliki rekaman arsitektur yang ingin dilestarikan. Upaya ini dapat dilakukan dengan rekaman gambar, foto, model, wawancara, video atau virtual reality. Lebih lanjut, upaya ini sejalan dengan gerakan DOCOMOMO (Documentation and Conservation of Monuments and Sites of the Modern Movement). Gerakan dokumentasi ini bisa dilakukan dengan melakukan dokumentasi seluruh artefak yang ada sebagai jalan untuk melakukan pemeringkatan artefak dan cagar budaya sesuai dengan amanat undang-undang cagar budaya.

Berdasarkan identifikasi pada artikel jurnal terseleksi, model pelestarian cagar budaya cenderung menunjukan pada model zonasi, perawatan dan pemugaran situs cagar budaya. Sebagian besar artikel jurnal terseleksi menegaskan pelestarian bangunan cagar budaya adalah fokus pada bentuk dan wujud bangunan tersebut. Padahal, nilai-nilai sejarah dan informasi yang terkandung dalam bangunan tersebut dapat dilihat dan dipahami melalui arsip dan dokumen mengenai situs cagar budaya tersebut. Terdapat dua artikel jurnal terseleksi yang menjelaskan arsip dan dokumen sebagai model pelestarian cagar budaya. Kedua artikel tersebut menjelaskan pentingnya arsip dalam pelestarian cagar budaya, sehingga perlu adanya digitalisasi arsip (Fahmawati, 2018) dan pembuatan buku referensi mengenai situs cagar budaya (Septiawan, 2015).

Salah satu faktor yang menjadi tantangan dalam pelestarian cagar budaya yang ditunjukan oleh artikel terseleksi adalah tidak tersedianya informasi dan dokumen yang memadai mengenai bangunan cagar budaya yang bersangkutan. Meskipun hanya tercantum pada dua artikel jurnal terseleksi, hal ini menegaskan keberadaan dokumen atau arsip memegang peranan penting dalam pelestarian cagar budaya. Salah satu artikel jurnal terseleksi menyebutkan bahwa dokumentasi adalah cara yang efektif untuk pelestarian arsitektur bersejarah, terutama ketika arsitektur tersebut secara sosial tidak berhasil mengangkat kualitas lingkungan dan kehidupan sosial (Zain, 2014). Keberadaan dokumen atau arsip mengenai cagar budaya yang bersangkutan dapat menjadi salah satu bentuk ikhtiar pelestarian nilai-nilai sejarah dan informasi dari bangunan cagar budaya tersebut.

\section{KESIMPULAN}

Arsip memiliki peranan penting dalam pelestarian cagar budaya. Arsip menyimpan informasi mengenai nilai sejarah dan perkembangan pembangunan situs cagar budaya yang bersangkutan. Namun, belum banyak penelitian di Indonesia terkait pelestarian cagar budaya yang mengulas peranan arsip dalam pelestarian cagar budaya. Hal tersebut ditunjukan pada artikel jurnal terseleksi dalam penelitian ini yang cenderung menggunakan arsip berupa regulasi pemerintah mengenai pelestarian cagar budaya sebagai dokumen acuan utama. Artikel jurnal terseleksi lebih banyak fokus pada pelestarian wujud bangunan cagar budaya. Adapun model pelestarian cagar budaya yang cenderung digunakan dalam artikel jurnal terseleksi, yaitu: zonasi, perawatan, pemugaran, 
reformasi sumber daya manusia dan adanya regulasi yang jelas. Tantangan yang dihadapi dalam pelestarian cagar budaya yang teridentifikasi dalam artikel jurnal terseleksi, yaitu tidak adanya regulasi yang jelas, terbatasnya anggaran untuk pelestarian, terbatasnya ahli yang memahami cagar budaya, kurangnya kesadaran masyarakat mengenai pelestarian cagar budaya, rendahnya sinergi dari stakeholder, faktor lingkungan dan tidak adanya dokumen yang memadai mengenai cagar budaya yang bersangkutan.

\section{DAFTAR PUSTAKA}

Adrian, C., Abdullah, R., Atan, R., \& Jusoh, Y.Y. 2016. Towards Developing Strategic Assessment Model for Big Data Implementation: A Systematic Literature Review. International Journal Advance Software Computer Application, 8(3).

Al Hamid, A.D. 2018. Analisis Pengelolaan dan Pelestarian Bangunan Cagar Budaya oleh Pemerintah Kota Salatiga. Journal of Politic and Government Studies, 7(4).

ANRI,.I. 2012. Arsip "Penyelamat" Bangunan Sejarah. Majalah Arsip Media Kearsipan Nasional: Arsip dan Kearsitekturan, 57, Januari - April.

Apriadi, E. 2019. Pelestarian Cagar Budaya di Kotagede (Penelitian Deskriptif Kualitatif di Dinas Kebudayaan Kota Yogyakarta). Yogyakarta: Sekolah Tinggi Pembangunan Masyarakat Desa "APMD".

Cunningham, A. et. al. 2005. Modern Movement Heritage. London: Taylor \& Francis.

Effendhie, M. 2019. Publikasi dan Pameran Arsip. Tangerang: Universitas Terbuka.

Fatmawati, E. 2018. Arsip Pemugaran Candi Sebagai Pelestarian Cagar Budaya. Warta Arsip, VII (2), $12-16$.

Handayani, P.W. 2017. Systematic Review dengan PRISMA (Preferred Reporting Items for Systematic Reviews and Meta-Analyses. Makalah Workshop Riset Sistem Informasi Fakultas Ilmu Komputer UI, 1-3 Agustus.

Hastuti, K., Hidayat, E.Y., \& Rahmawan, E. 2013. Purwarupa Tangible Cultural Heritage Documentation berbasis Database Multimedia. Techno.COM, 12(4), 188-197.

Klassen, T.P., Jadad, A.R., \& Moher, D. 1998. Guides For Reading and Interpreting Systematic Reviews: I. Getting Started. Arch Pediatr Adolesc Med., 152(7), 700 - 704.

Krihanta, K. 2012. Arsip Kearsitekturan sebagai Bukti Sejarah Peradaban Suatu Bangsa. Majalah Arsip Media Kearsipan Nasional: Arsip dan Kearsitekturan, 57, Januari - April.

Krihanta, K. 2013. Pengelolaan Arsip Vital. Tangerang: Universitas Terbuka.

Mirawati, I. 2012. Melestarikan Cagar Budaya Jakarta Melalui Arsip. Majalah Arsip Media Kearsipan Nasional: Arsip dan Kearsitekturan, 57, Januari - April.

Petticrew, M. \& Roberts, H. 2006. Systematic Reviews in The Social Sciences. Malden, MA: Blackwell Publishing.

Republik-Indonesia, I. 2010. Undang-Undang Nomor 11 Tahun 2010 Tentang Cagar Budaya. Jakarta.

Risanti, N. A. 2011. Perlindungan Hukum Hak Cipta Terhadap Warisan Budaya Bangsa Indonesia Ditinjau dari Perspektif Hukum Internasional. Skripsi. Medan: Universitas Sumatera Utara.

Rowat, T. 1993. The Record and Repository as Cultural Form of Expression. Archivaria, 36, 198-204.

Septiawan, D.L., Bahruddin, M., \& Sutikno, S. 2015. Penciptaan Buku Referensi Masjid Tua Pada Abad XV Di Surabaya Sebagai Upaya Pelestarian Cagar Budaya. Jurnal Art Nouveau, 4(1) 
Sulistyanto, I., Krisnawati, E., \& Karsono, D. 2015. Pengaruh Perkembangan Permukiman Swadaya Terhadap Upaya Pelestarian Cagar Budaya Tamansari. Jurnal Permukiman, 10(1), 49-60.

UNESCO, U. 1992. World Heritage. di https://whc.unesco.org/ (akses 30 Mei 2020).

Wibowo, D.T. \& Christiani, L. 2018. Peran Arsip Digital Naskah Kuno Padawebsite Yayasan Sastra Lestari dalam Diseminasi Informasi Kesusastraan Jawa. Jurnal Ilmu Perpustakaan, 7(3), 211220.

Zain, Z. 2014. Strategi Perlindungan terhadap Arsitektur Tradisional untuk Menjadi Bagian Pelestarian Cagar Budaya Dunia. Jurnal Nalars, 13(1). 